\title{
A study of factors affecting the physical activity of youth: analysis of data from the 13th youth health behavior online survey in 2017
}

\author{
Min-Soo Cho' ${ }^{1}$, Ji-Youn Kim ${ }^{2 * *}$ \\ ${ }^{1}$ Liberal Arts College, Chungwoon University, Incheon, Korea \\ ${ }^{2}$ Exercise Rehabilitation Convergence Institute, Gachon University, Incheon, Korea
}

This study was intended to provide basic data to promote youth participation in physical activity by determining the factors that affect the physical activities of Korean youth. To achieve the purpose of this study, data obtained from the 13th Youth Health Behavior Online Survey in 2017 was used as raw data and data on 62,276 youths were analyzed by frequency analysis, chi-square test, and logistic regression analysis using IBM SPSS Statistics ver. 22.0. The results suggested gender $(P<0.001)$, school grade $(P<0.001)$, and residential type $(P<0.001)$ in general characteristics; subjective health status $(P<0.001)$, stress perception $(P<0.001)$, and sleep satisfaction $(P<0.001)$; and finally drinking experience $(P<0.004)$, smoking experience $(P<0.009)$, and skipping breakfast in the morning $(P<0.009)$ as factors affecting Korean youth's participation in physical activity. These results indicate that: male students participated in physical activities more than female students, and middle school students participated in physical activities more than high school students; students with a higher economic status and academic performance participated more in physical activities; and students with higher subjective health status, higher happiness, and higher sleep satisfaction, students who did not drink or smoke, and students who had breakfast participated more in physical activities.

Keywords: Physical activity, Health behavior, Health-related behavior factors, Adolescence, Youth health behavior, Online survey

\section{INTRODUCTION}

Adolescence is an important period for physical and mental growth, such as the developmentof secondary sexual characteristics, sexual maturity and cognitive function, emotional independence development, and self-identity formation (Currie and Alemán-Díaz, 2015). In particular, since identity is not fully established in this period, health risk behaviors experienced at this time are easily learned, and as the acquired lifestyle leads to adulthood, the lifestyle and health promotion behaviors acquired during this period are very important (Viner et al., 2015).

In general, regular physical activity in adolescence is critical to health development. Physical activity during this period has been found to be highly correlated with physical, mental, social, and lifestyle development (Bailey, 2006; Strong et al., 2005). However, it was found that Korean youth had the shortest time of participating in physical activities (Ministry for Health and Welfare, 2009), compared with those in the United States, the United Kingdom, Germany, Sweden, and Finland.

Despite the results of studies that found that long-term sedentary living, resulting in a lack ofphysical activity, is harmful to health (Bélanger et al., 2015) and sleep satisfaction is required for normal development and growth (Carson et al., 2015; Saunders et al., 2016), Korean youth's participation in physical activity is declining. According to the results of an online survey youth health behaviors conducted by the Ministry of Health and Welfare every year, the percentage of students who did not attend physical education classes per week increased to $18 \%$ and $27.4 \%$ for male and
${ }^{*}$ Corresponding author: Ji-Youn Kim (D) https://orcid.org/0000-0003-2325-1921 Exercise Rehabilitation Convergence Institute, Gachon University,

191 Hambangmoe-ro, Yeonsu-gu, Incheon 21936, Korea

E-mail: eve14jiyoun@naver.com

Received: December 13, 2018 / Accepted: January 22, 2019
This is an Open Access article distributed under the terms of the Creative Commons Attribution Non-Commercial License (http://creativecommons.org/licenses/by-nc/4.0/) which permits unrestricted non-commercial use, distribution, and reproduction in any medium, provided the original work is properly cited. 
female middle-high school students, respectively, in 2012 from $12.1 \%$ and $15.9 \%$ in 2005 (Korea Centers for Disease Control and Prevention, 2012).

The decrease in youth participation in physical activity has been reported to have various effects on mental health. In particular, Korean youth have been reported to have very low satisfaction and low happiness in life as they experience academic stress and a lack of leisure culture (Park et al., 2018). In fact, among Organization for Economic Co-operation and Development (OECD) member countries in 2015, the subjective happiness of Korean youth has been reported to be at the lowest level (OECD, 2018). Physical activity affects physical and mental health status such as subjective health, depression, and stress (Asare and Danquah, 2015), and also affects health behaviors such as smoking, drinking, eating habits, and drug use acquired during this period (Larson et al., 2014; Marques et al., 2018). In particular, the lifestyle established in this period affects the lifestyle in adulthood (Currie and Alemán-Díaz, 2015), having a great influence on life as a complementary concept to health and quality of life in the future. The results of these studies show that the factors that affect participation in physical activities are closely related to the lifestyle of youth in a diverse and complex manner, suggesting that it is necessary to obtain representative data for establishing and evaluating youth policies at the national level.

Thus, this study was intended to examine the factors affecting Korean youth's participation in physical activity based on the data from an online survey on Korean youth behavior first conducted in 2005 by the Korea Centers for Disease Control \& Prevention for middle and high school students nationwide with the aim of improving the health of the youth who will lead the future. For this purpose, this study was intended to analyze the factors that affect youth participation in physical activities using the data obtained from the 13th Youth Health Behavior Online Survey in 2017 as raw data. To analyze the factors that affect participation in physical activities, the factors were categorized into health status factors including the general characteristics of the subjects, subjective happiness, stress perception, sleep satisfaction and experience of depression, and health-related behavior factors including drinking, smoking, drugs and diet. The results of this study are expected to provide basic data that can be used to study specific strategies to promote youth participation in physical activities for the health of the youth.

\section{MATERIALS AND METHODS}

To analyze the effects of mental health characteristics of Korean youth on physical activity, this study analyzed data obtained from the 13th Youth Health Behavior Online Survey in 2017.

\section{Study subjects}

The subjects of this study were middle and high school students nationwide as of April 2017. For the sampling process, one class per grade was sampled at random from 400 middle schools and 400 high schools, and all students in the classes were investigated. Students who were on long-term absence, special students and students with letter decoding disability were excluded from the sample. As a result, 30,885 middle school students and 31,391 high school students were selected as subjects.

\section{Study tool}

The 13th Youth Health Behavior Online Survey in 2017 consists of a total of 123 questions in 15 areas: smoking, drinking, physical activity, dietary life, obesity and weight control, mental health, damage and safety awareness, oral health, personal hygiene, drugs, sexual behavior, atopy, Internet addiction, health equity, etc. This study used the variables presented in the raw data to manipulate the mental health-related items, physical activity and personal characteristics of youth as factors.

\section{Physical activity}

Physical activity was categorized into "whether there was a day in which the heart rate increased compared to normal time over the last 7 days" and "whether there was a day in which the subject participated in physical activity for more than $60 \mathrm{~min} . "$

\section{General characteristics}

For the general characteristics of the subjects, gender, school grade, subjective academic performance, residential type, and subjective economic status of the subjects were analyzed. The school grade was categorized into middle school and high school, and the subjective academic performance and the subjective economic status were reconstructed into a three-level category from a five-level category. For residential type, the raw data that was categorized into living with the family, living with relatives, boarding houses, living alone, dormitories, caring facilities (orphanages, social welfare facilities, nurseries) was used as it was.

\section{Health status factors}

Health status factors consisted of subjective health perception, subjective happiness, stress perception, subjective sleep satisfaction, and depression. Subjective health perception, subjective hap- 
piness, stress perception, and subjective sleep satisfaction were reconstructed into three categories from five categories. For depression, it was categorized into "whether the subject had a feeling of sadness or despair to stop daily life for 2 weeks in the last 12 months."

\section{Health-related behavior factors}

The health-related behavior factors were about drinking experience, smoking experience, drug use experience, and skipping breakfast in the raw data. And they were reconstructed by categorizing them into whether the subject had such experiences.

\section{Data processing}

The data collected was analyzed using the IBM SPSS Statistics ver. 22.0 (IBM Co., Armonk, NY, USA). The frequency and percentage of the subjects' general characteristics, health status, health-related behaviors, and physical activity experiences were calculated. The relationship between general characteristics and health status, health-related behaviors and physical activities was analyzed by chi-square test. To determine the effect of the general characteristics, health status and health-related behaviors on the physical activity, composite sample logistic regression analysis was conducted to calculate the odds ratio (OR) and the $95 \%$ confidence interval (CI) was calculated. The significance level of all statistical analyses was set at $P<0.05$.

\section{RESULTS}

\section{General characteristics of the study subject}

The general characteristics of subjects are summarized in Table 1. The gender of the subjects was $50.8 \%$ for males, $49.2 \%$ for females, $49.6 \%$ for middle school students and $50.4 \%$ for high school students. For residential type, living with family accounted for the largest percentage (95.0\%) followed by boarding house, living along, and dormitories (3.7\%), living with relatives ( $0.8 \%)$ and caring facilities $(0.5 \%)$. The subjective economic status was in the order of middle (45.9\%), high (39.8\%), and low (14.3\%), and the subjective academic performance was in the order of high (39.4\%), low (32.0\%), and middle (28.6\%).

For health status and subjective happiness in the health-related factors, $72.1 \%$ and $67.6 \%$ replied they were healthy and they were happy, respectively, whereas $25.1 \%$ replied that they experienced depression. For stress perception, $79.5 \%$ replied that subjective sleep satisfaction was "normal" or "much," while $74.1 \%$ replied "not normal" and "insufficient."
Table 1. Characteristics of the study subjects $(n=62,276)$

\begin{tabular}{|c|c|}
\hline Variable & №. $(\%)$ \\
\hline \multicolumn{2}{|l|}{ Sex } \\
\hline Male & $31,624(50.8)$ \\
\hline Female & 30,652 (49.2) \\
\hline \multicolumn{2}{|l|}{ Education } \\
\hline Middle school & $30,885(49.6)$ \\
\hline High school & 31,391 (50.4) \\
\hline \multicolumn{2}{|l|}{ Living type } \\
\hline With family & $59,162(95.0)$ \\
\hline With relatives & $496(0.8)$ \\
\hline Lodging or self-lodging & 2,301 (3.7) \\
\hline Childcare facilities & $317(0.5)$ \\
\hline \multicolumn{2}{|l|}{ Economic status } \\
\hline High & 24,802 (39.8) \\
\hline Middle & 28,582 (45.9) \\
\hline Low & $8,892(14.3)$ \\
\hline \multicolumn{2}{|l|}{ Subjective school record } \\
\hline High & 24,524 (39.4) \\
\hline Middle & $17,810(28.6)$ \\
\hline Low & $19,942(32.0)$ \\
\hline \multicolumn{2}{|l|}{ Subjective health status } \\
\hline High & $44,913(72.1)$ \\
\hline Middle & $13,417(21.6)$ \\
\hline Low & 3,946 (6.3) \\
\hline \multicolumn{2}{|l|}{ Depression } \\
\hline No & $46,664(74.9)$ \\
\hline Yes & $15,612(25.1)$ \\
\hline \multicolumn{2}{|l|}{ Subjective happiness } \\
\hline Happy & 42,137 (67.6) \\
\hline Moderate & 15,309 (24.6) \\
\hline Unhappy & 4,830 (7.8) \\
\hline \multicolumn{2}{|l|}{ Perceived stress } \\
\hline High & $23,259(37.3)$ \\
\hline Moderate & $26,271(42.2)$ \\
\hline Enough & $12,746(20.5)$ \\
\hline \multicolumn{2}{|l|}{ Sufficiency of sleep } \\
\hline Enough & $16,148(25.9)$ \\
\hline Moderate & 20,052 (32.2) \\
\hline Not enough & 26,076 (41.9) \\
\hline \multicolumn{2}{|l|}{ Physical activity } \\
\hline No & $22,397(36.0)$ \\
\hline Yes & $39,879(64.0)$ \\
\hline \multicolumn{2}{|l|}{ Alcohol use } \\
\hline No & 37,859 (60.8) \\
\hline Yes & 24,417 (39.2) \\
\hline \multicolumn{2}{|l|}{ Smoking } \\
\hline No & $54,126(86.9)$ \\
\hline Yes & $8,150(13.1)$ \\
\hline \multicolumn{2}{|l|}{ Drug use } \\
\hline No & 61,927 (99.4) \\
\hline Yes & $349(0.6)$ \\
\hline \multicolumn{2}{|l|}{ Breakfast } \\
\hline No & $8,712(14.0)$ \\
\hline Yes & $53,564(86.0)$ \\
\hline
\end{tabular}


For the experience of physical activity in the health-related behavior factors, $64.0 \%$ of all youth participated in physical activity more than 60 min a week, 39.2\% experienced drinking, and $13.1 \%$ had smoked. For drug use, 349 respondents (0.6\%) experienced drugs, and $86.0 \%$ had breakfast at least once a week.

\section{Physical activity according to general characteristics, health status factor, and health-related behavior}

Differences between general characteristics and physical activity experiences according to health status are listed in Table 2. There were significant differences in gender $(P<0.001)$, school grade $(P<0.001)$, residential type $(P<0.001)$, subjective economic status $(P<0.001)$, and subjective academic performance $(P<0.001)$ in the experience of physical activity. In the health-related status factor, there were significant differences in subjective health status $(P<0.001)$, subjective happiness $(P<0.001)$, stress perception $(P<$ $0.001)$ and sleep satisfaction $(P<0.001)$. And there was no significant difference in participation in physical activity and the experience of distress. Finally, for the difference of physical activity experience in health-related behavior, there was a significant difference in skipping breakfast and $(P<0.001)$ and drinking experience $(P<0.026)$.

\section{Factors affecting physical activity of youth}

To examine the effect of the general characteristics, health-related factors, and health-related behavior factors on participation in physical activity, logistic regression analysis was conducted (Table 3). The results are as follows: First, male students participated in physical activities more than female students $(P<0.001)$, and high school students showed a lower physical activity participation rate than middle school students $(P<0.001)$. Participation in physical activity was higher among students living in boarding houses, living alone, and living in dormitories than students living with family $(P<0.001)$. In the health-related factors, students with higher subjective health status $(P<0.001)$ and subjective happiness participated more in physical activity, and in sleep satisfaction factor, students who were satisfied with their sleep participated more in physical activity, while students with a high level of stress participated more than those with lower levels of stress. In the health-related behavior factor, students who did not drink $(P<0.004)$, students who did not smoke $(P<0.009)$, and those who had breakfast participated more in physical activity $(P<0.001)$.
Table 2. Differences in subjective physical activity to health status, and health related behavior factor

\begin{tabular}{|c|c|c|c|}
\hline \multirow{2}{*}{ Variable } & \multicolumn{2}{|c|}{ Physical activity } & \multirow{2}{*}{$\chi^{2}(P$-value $)$} \\
\hline & No & Yes & \\
\hline \multicolumn{4}{|l|}{ Sex } \\
\hline Male & $8,756(39.1)$ & $22,868(57.3)$ & \multirow{2}{*}{$1,910.973(0.001)^{* * *}$} \\
\hline Female & $13,641(60.9)$ & $17.011(42.7)$ & \\
\hline \multicolumn{4}{|l|}{ School } \\
\hline Middle school & $10,580(47.2)$ & $20,305(50.9)$ & \multirow[t]{2}{*}{$77.641(0.001)^{* * *}$} \\
\hline High school & $11,817(52.8)$ & $19,574(49.1)$ & \\
\hline \multicolumn{4}{|l|}{ Living type } \\
\hline With family & 21,381 (95.5) & 37,781 (94.7) & \multirow[t]{4}{*}{$16.455(0.001)^{* * * *}$} \\
\hline With relatives & $155(0.7)$ & $341(0.9)$ & \\
\hline Lodging or self-lodging & $754(3.4)$ & $1,547(3.9)$ & \\
\hline Childcare facilities & $107(0.5)$ & $210(0.5)$ & \\
\hline \multicolumn{4}{|l|}{ Economic status } \\
\hline High & $8,458(37.8)$ & $16,344(41.0)$ & \multirow[t]{3}{*}{$63.952(0.001)^{* * *}$} \\
\hline Middle & $10,577(47.2)$ & $18,005(45.1)$ & \\
\hline Low & $3,362(15.0)$ & $5,530(13.9)$ & \\
\hline \multicolumn{4}{|l|}{ Subjective school record } \\
\hline High & $8,254(36.9)$ & $16,270(40.8)$ & \multirow[t]{3}{*}{$112.003(0.001)^{* * * *}$} \\
\hline Middle & $6,472(28.9)$ & $11,338(28.4)$ & \\
\hline Low & 7,671 (34.3) & $12,271(30.8)$ & \\
\hline \multicolumn{4}{|l|}{ Subjective health status } \\
\hline High & $15,003(67.0)$ & $29,910(75.0)$ & \multirow[t]{3}{*}{$469.927(0.001)^{* * *}$} \\
\hline Middle & $5,623(25.1)$ & 7,794 (19.5) & \\
\hline Low & $1,771(7.9)$ & $2,175(5.5)$ & \\
\hline \multicolumn{4}{|l|}{ Subjective happiness } \\
\hline Happy & $14,207(63.4)$ & $27,930(70.0)$ & \multirow[t]{3}{*}{$292.861(0.001)^{* * *}$} \\
\hline Moderate & $6,149(27.5)$ & $9,160(23.0)$ & \\
\hline Unhappy & $2,041(9.1)$ & $2,789(7.0)$ & \\
\hline \multicolumn{4}{|l|}{ Perceived stress } \\
\hline High & 8,889 (39.7) & $14,370(36.0)$ & \multirow[t]{3}{*}{$94.128(0.001)^{* * *}$} \\
\hline Moderate & $9,251(41.3)$ & $17,020(42.7)$ & \\
\hline Low & $4,257(19.0)$ & $8,489(21.3)$ & \\
\hline \multicolumn{4}{|l|}{ Sufficiency of sleep } \\
\hline Enough & $5,521(24.7)$ & $10,627(26.6)$ & \multirow[t]{3}{*}{$92.644(0.001)^{* * *}$} \\
\hline Moderate & 6,931 (30.9) & $13,121(32.9)$ & \\
\hline Not enough & $9,945(16.0)$ & $16,131(40.4)$ & \\
\hline Depression & & & \\
\hline No & $16,875(75.3)$ & $29,789(74.7)$ & $3.191(0.075)$ \\
\hline Yes & $5,522(24.7)$ & $10,090(25.3)$ & \\
\hline Alcohol use & & & \\
\hline No & $11,779(60.1)$ & $26,080(61.1)$ & $4.958(0.026)^{*}$ \\
\hline Yes & 7,804 (39.9) & $16,613(38.9)$ & \\
\hline Smoking & & & \\
\hline No & 17,087 (87.3) & 37,039 (86.8) & 2.923 (0.089) \\
\hline Yes & $2,496(12.7)$ & $5,654(13.2)$ & \\
\hline Drug use & & & \\
\hline No & 19,486 (99.5) & 42,441 (99.4) & $2.171(0.141)$ \\
\hline Yes & $97(0.5)$ & $252(0.6)$ & \\
\hline Breakfast & & & \\
\hline No & $2,951(15.1)$ & $5,761(13.5)$ & $27.684(0.001)^{* * *}$ \\
\hline Yes & 16,632 (84.9) & 36,932 (86.5) & \\
\hline
\end{tabular}

${ }^{*} P<0.05 .{ }^{* *} P<0.001$. 
Table 3. Factors affecting physical activity of youth

\begin{tabular}{|c|c|c|c|c|c|}
\hline Variable & $\beta$ & SE & OR & $95 \% \mathrm{Cl}$ & $P$-value \\
\hline \multicolumn{6}{|l|}{ Sex (ref: female) } \\
\hline Male & 0.739 & 0.017 & 2.094 & $2.026-2.165$ & $0.001^{* * *}$ \\
\hline \multicolumn{6}{|l|}{ School (ref: middle school) } \\
\hline High school & -0.147 & 0.017 & 0.863 & $0.835-0.892$ & $0.001^{* * *}$ \\
\hline \multicolumn{6}{|c|}{ Living type (ref: with family) } \\
\hline With relatives & 0.219 & 0.097 & 1.029 & $1.029-1.206$ & 0.024 \\
\hline Lodging or self-lodging & 0.149 & 0.045 & 1.161 & $1.063-1.269$ & $0.001^{* * *}$ \\
\hline Childcare facilities & 0.105 & 0.119 & 1.111 & $0.879-1.403$ & 0.378 \\
\hline \multicolumn{6}{|l|}{ Economic status (ref: high) } \\
\hline Middle & -0.094 & 0.019 & 0.910 & $0.878-0.944$ & $0.001^{* * *}$ \\
\hline Low & -0.110 & 0.026 & 0.896 & $0.851-0.943$ & $0.001^{* * *}$ \\
\hline \multicolumn{6}{|c|}{ Subjective school record (ref: high) } \\
\hline Middle & -0.100 & 0.210 & 0.905 & $0.869-0.943$ & $0.001^{* * *}$ \\
\hline Low & -0.182 & 0.020 & 0.834 & $0.801-0.868$ & $0.001^{* * *}$ \\
\hline \multicolumn{6}{|c|}{ Subjective health status (ref: low) } \\
\hline High & 0.438 & 0.034 & 1.550 & $1.448-1.658$ & $0.001^{* * *}$ \\
\hline Middle & 0.098 & 0.037 & 1.103 & $1.026-1.185$ & $0.008^{* *}$ \\
\hline \multicolumn{6}{|c|}{ Subjective happiness (ref: unhappy) } \\
\hline Happy & 0.364 & 0.031 & 1.439 & $1.354-1.528$ & $0.001^{* * *}$ \\
\hline Moderate & 0.086 & 0.033 & 1.090 & $1.021-1.164$ & $0.010^{* *}$ \\
\hline \multicolumn{6}{|l|}{ Perceived stress (ref: high) } \\
\hline Low & 0.129 & 0.019 & 1.138 & $1.097-1.181$ & $0.001^{* * *}$ \\
\hline Moderate & 0.210 & 0.023 & 1.234 & $1.179-1.291$ & $0.001^{* * *}$ \\
\hline \multicolumn{6}{|c|}{ Sufficiency of sleep (ref: no enough) } \\
\hline Enough & 0.074 & 0.022 & 1.076 & $1.030-1.124$ & $0.001^{* * *}$ \\
\hline Moderate & 0.103 & 0.020 & 1.108 & $1.066-1.153$ & $0.001^{* * *}$ \\
\hline \multicolumn{6}{|l|}{ Depression (ref: yes) } \\
\hline No & 0.034 & 0.019 & 1.035 & $0.997-1.075$ & 0.074 \\
\hline \multicolumn{6}{|l|}{ Health related behavior } \\
\hline Alcohol use, no & 0.055 & 0.019 & 1.057 & 1.018-1.097 & $0.004^{* *}$ \\
\hline Smoking, no & -0.073 & 0.028 & 0.930 & $0.880-0.982$ & $0.009^{* *}$ \\
\hline Drug use, no & -0.159 & 0.121 & 0.853 & $0.673-0.982$ & 0.188 \\
\hline Breakfast, yes & 0.128 & 0.025 & 1.137 & 1.083-1.192 & $0.001^{* * *}$ \\
\hline
\end{tabular}

$\mathrm{SE}$, standard error; $\mathrm{OR}$, odds ratio; $\mathrm{Cl}$, confidence interval.

${ }^{* *} P<0.01 .{ }^{* * *} P<0.001$.

\section{DISCUSSION}

This study was intended to examine the factors affecting youth participation in physical activity according to general characteristics, health status, and health-related behavior factors, and to suggest strategies for promoting the health of youth.

First, in the general characteristics of the subjects, gender, school grade, subjective economic status, living alone, living in a dormitory, and subjective academic performance were suggested as factors affecting the physical activity participation of youth. In other words, male students participated more in physical activities than female students, and the higher the economic status and subjective academic performance, the higher the participation in physical activity. Lee et al. (2016) reported in their study that participation in physical activity decreased after puberty, and Park (2014) reported that male students and students in lower grades participated more in physical activities than female students and students in higher grades, while students with higher economic status and higher subjective academic performance participated more in physical activity. In addition, the results of this study show that middle school students participated more in physical activity than high school students. These results are supported by the results of prior studies reporting that the higher the school grade, the lower the participation in physical activity due to stress from study and daily tasks (Park, 2014).

Second, health status factors including subjective health status, subjective happiness, depression, sleep, and stress affected youth participation in physical activity. In other words, the higher the subjective health status, the lesser the distress, and the higher the sleep satisfaction and the lower the stress, the higher the participation in physical activity. In prior studies, participation in physical activity was associated with higher subjective health, and low participation in physical activity was associated with lower subjective health (Abu-Omar et al., 2004). Biddle and Asare (2011) reported that physical activity can relieve the depression and anxiety of children and youth. The study of Carson et al. (2016) on Canadian youth reported significant differences in health index between sleep, sitting time and physical activity time. The results of this study were supported by the results of prior studies reporting that regular physical activity was associated with better subjective health perception (Tsai et al., 2010), whereas those who participate less in physical activity maintained a lower health perception status (Han et al., 2009).

Third, in health-related behaviors, drinking, smoking experience, and skipping breakfast affected youth participation in physical activity. In other words, those who did not drink and smoke, and those who had breakfast participated more in physical activity. Improper behaviors such as drinking, smoking, and drug use are the factors that make the physical health as well as mental health of the youth vulnerable. López Villalba et al. (2016) reported that physical activity positively correlates with low alcohol consumption for boys and girls in adolescence, and the result was higher in male youth than female youth. In addition, physical activity is also used to control smoking. Blank et al. (2017) reported positive effects of interventions using physical activity to reduce 
smoking among youth. In addition, skipping breakfast is a major negative factor affecting health, resulting in negative effects on food intake and body mass index (Rampersaud et al., 2005) and skipping breakfast may affect long-term health (Smith et al., 2010), thus, proper health behaviors of youth are important. Smith et al. (2017) reported that when students, especially those in the upper grades, were not satisfied with their sleep, they participated less in physical activity, and skipped breakfast, which was also affected by lower household income and single parent families.

The results of prior studies showed that physical activity decreased significantly between 11 and 15 years of age in adolescence, and health-related behaviors also linearly decreased (Marques et al., 2018). This phenomenon is not occurring only in Korea, but it is important to recognize and solve the physical activity participation factors for the health of the youth, since Korean youth's physical activity participation time is the shortest in the world. As a result of this study, it was found that health status and health-related activities other than general characteristics affecting physical activity are closely correlated with each other, and physical activity has a moderating effect, thus, education on its importance and support are important.

This study is meaningful in that it provides empirical basic data to promote the participation of youth in physical activity by determining the factors that affect their participation in physical activity. However, this study has some limitations in that it does not include various factors affecting the physical activities of youth by proceeding through secondary data analysis, and there might be errors in measurement as this study measured variables with single questions. In addition, there is a limit to mention the results as causal relationships as they are the results of a cross-sectional study.

\section{CONFLICT OF INTEREST}

No potential conflict of interest relevant to this article was reported.

\section{REFERENCES}

Abu-Omar K, Rütten A, Robine JM. Self-rated health and physical activity in the European Union. Soz Praventivmed 2004;49:235-242.

Asare M, Danquah SA. The relationship between physical activity, sedentary behaviour and mental health in Ghanaian adolescents. Child Adolesc Psychiatry Ment Health 2015;9:11.
Bailey R. Physical education and sport in schools: a review of benefits and outcomes. J Sch Health 2006;76:397-401.

Bélanger M, Sabiston CM, Barnett TA, O'Loughlin E, Ward S, Contreras G, O'Loughlin J. Number of years of participation in some, but not all, types of physical activity during adolescence predicts level of physical activity in adulthood: Results from a 13-year study. Int J Behav Nutr Phys Act 2015;12:76.

Biddle SJ, Asare M. Physical activity and mental health in children and adolescents: a review of reviews. Br J Sports Med 2011;45:886-895.

Blank MD, Ferris KA, Metzger A, Gentzler A, Duncan C, Jarrett T, Dino G. Physical activity and quit motivation moderators of adolescent smoking reduction. Am J Health Behav 2017;41:419-427.

Carson V, Staiano AE, Katzmarzyk PT. Physical activity, screen time, and sitting among U.S. adolescents. Pediatr Exerc Sci 2015;27:151-159.

Carson V, Tremblay MS, Chaput JP, Chastin SF. Associations between sleep duration, sedentary time, physical activity, and health indicators among Canadian children and youth using compositional analyses. Appl Physiol Nutr Metab 2016;41(6 Suppl 3):S294-302.

Currie C, Alemán-Díaz AY. Building knowledge on adolescent health: reflections on the contribution of the Health Behaviour in School-aged Children (HBSC) study. Eur J Public Health 2015;25 Suppl 2:4-6.

Han MA, Kim KS, Park J, Kang MG, Ryu SY. Association between levels of physical activity and poor self-rated health in Korean adults: The Third Korea National Health and Nutrition Examination Survey (KNHANES), 2005. Public Health 2009;123:665-669.

Korea Centers for Disease Control and Prevention. Korea youth risk behavior web-based survey: survey summaries. Cheongwon (Korea): Korea Centers for Disease Control and Prevention; 2012.

Larson N, Dewolfe J, Story M, Neumark-Sztainer D. Adolescent consumption of sports and energy drinks: linkages to higher physical activity, unhealthy beverage patterns, cigarette smoking, and screen media use. J Nutr Educ Behav 2014;46:181-187.

Lee EY, An K, Jeon JY, Rodgers WM, Harber VJ, Spence JC. Biological maturation and physical activity in South Korean adolescent girls. Med Sci Sports Exerc 2016;48:2454-2461.

López Villalba FJ, Rodríguez García PL, García Cantó E, Pérez Soto JJ. Relationship between sport and physical activity and alcohol consumption among adolescents students in Murcia (Spain). Arch Argent Pediatr 2016;114:101-106.

Marques A, Loureiro N, Avelar-Rosa B, Naia A, Matos MG. Adolescents' healthy lifestyle. J Pediatr (Rio J) 2018 Oct 27 [Epub]. pii: S0021-7557 (18)30768-X. https://doi.org/10.1016/j.jped.2018.09.002.

Ministry for Health and Welfare. The state of Korean children and adolescents. Seoul (Korea): Ministry for Health and Welfare; 2009.

Organization for Economic Co-operation and Development. OECD stat. 
Retrieved Nov. 10, 2018 [Internet]. Paris: Organization for Economic Co-operation and Development; [cited 2018 Oct 18]. Available from: http://stats.oecd.org.

Park S. Associations of physical activity with sleep satisfaction, perceived stress, and problematic Internet use in Korean adolescents. BMC Public Health 2014;14:1143.

Park S, Jang H, Lee ES. Major stressors among Korean adolescents according to gender, educational level, residential area, and socioeconomic status. Int J Environ Res Public Health 2018;15:2080.

Rampersaud GC, Pereira MA, Girard BL, Adams J, Metzl JD. Breakfast habits, nutritional status, body weight, and academic performance in children and adolescents. J Am Diet Assoc 2005;105:743-760.

Saunders TJ, Gray CE, Poitras VJ, Chaput JP, Janssen I, Katzmarzyk PT, Olds T, Connor Gorber S, Kho ME, Sampson M, Tremblay MS, Carson V. Combinations of physical activity, sedentary behaviour and sleep: relationships with health indicators in school-aged children and youth. Appl Physiol Nutr Metab 2016;41(6 Suppl 3):S283-293.

Smith KJ, Breslin MC, McNaughton SA, Gall SL, Blizzard L, Venn AJ.
Skipping breakfast among Australian children and adolescents; findings from the 2011-12 National Nutrition and Physical Activity Survey. Aust N Z J Public Health 2017;41:572-578.

Smith KJ, Gall SL, McNaughton SA, Blizzard L, Dwyer T, Venn AJ. Skipping breakfast: longitudinal associations with cardiometabolic risk factors in the Childhood Determinants of Adult Health Study. Am J Clin Nutr 2010;92:1316-1325.

Strong WB, Malina RM, Blimkie CJ, Daniels SR, Dishman RK, Gutin B, Hergenroeder AC, Must A, Nixon PA, Pivarnik JM, Rowland T, Trost $\mathrm{S}$, Trudeau F. Evidence based physical activity for school-age youth. J Pediatr 2005;146:732-737.

Tsai J, Ford ES, Li C, Zhao G, Balluz LS. Physical activity and optimal selfrated health of adults with and without diabetes. BMC Public Health 2010;10:365.

Viner RM, Ross D, Hardy R, Kuh D, Power C, Johnson A, Wellings K, McCambridge J, Cole TJ, Kelly Y, Batty GD. Life course epidemiology: recognising the importance of adolescence. J Epidemiol Community Health 2015;69:719-720. 